\title{
Pharmacokinetics of Boldine in Control and Mrp2-Deficient Rats
}

\author{
J. CERMANOVA ${ }^{1}$, A. PRASNICKA ${ }^{1}$, E. DOLEZELOVA ${ }^{3}$, L. ROZKYDALOVA $^{1,4}$, \\ M. HROCH ${ }^{2}$, J. CHLÁDEK ${ }^{1}$, P. TOMSIK ${ }^{2}$, I. KLOETING ${ }^{5}$, S. MICUDA $^{1}$
}

${ }^{1}$ Department of Pharmacology, ${ }^{2}$ Department of Medical Biochemistry, Faculty of Medicine, Charles University, Hradec Kralove, Czech Republic, ${ }^{3}$ Department of Biological and Medical Sciences, ${ }^{4}$ Department of Pharmacology and Toxicology, Faculty of Pharmacy, Charles University, Hradec Kralove, Czech Republic, ${ }^{5}$ The Institute of Pathophysiology, University Medicine Greifswald, Karlsburg, Germany

Received October 1, 2016

Accepted October 22, 2016

\section{Summary}

The aim of the present study was to describe the currently poorly understood pharmacokinetics (PK) of boldine in control rats (LW, Lewis rats), and Mrp2 transporter-deficient rats (TR'). Animals from the LW and TR' groups underwent a bolus dose study with $10 \mathrm{mg} / \mathrm{kg}$ of boldine applied either orally or intravenously in order to evaluate the major PK parameters. The TR rats demonstrated significantly reduced total clearance with prolonged biological halflife (LW $12 \pm 4.6$ versus TR' $20 \pm 4.4 \mathrm{~min}$ ), decreased volume of distribution (LW $3.2 \pm 0.4 \mathrm{l} / \mathrm{kg}$ versus TR' $2.4 \pm 0.4 \mathrm{l} / \mathrm{kg}$ ) and reduced bioavailability (LW $7 \%$ versus TR $4.5 \%$ ). Another set of LW and $\mathrm{TR}^{-}$rats were used for a clearance study with continuous intravenous administration of boldine. The LW rats showed that biliary and renal clearance formed less than $2 \%$ of the total clearance of boldine. The treatment of samples with $\beta$-glucuronidase showed at least a $38 \%$ contribution of conjugation reactions to the overall clearance of boldine. The $\mathrm{TR}^{-}$rats demonstrated reduced biliary clearance of boldine and its conjugates, which was partly compensated by their increased renal clearance. In conclusion, this study presents the PK parameters of boldine and shows the importance of the Mrp2 transporter and conjugation reactions in the elimination of the compound.

\section{Key words}

Boldine • Mrp2 • Pharmakokinetics • Elimination • Bioavailibility

\section{Corresponding author}

S. Micuda, Department of Pharmacology, Charles University, Faculty of Medicine, Simkova 870, 50003 Hradec Kralove, Czech Republic. E-mail: micuda@lfhk.cuni.cz

\section{Introduction}

Boldine is an alkaloid isolated from the leaf and bark of the Chilean Boldo tree (Peumus boldus Molina, Monimiaceae). The agent has shown positive effects on several preclinical in vitro and in vivo models of different pathologies such as hepatotoxicity (Lanhers et al. 1991, Fernandez et al. 2009, Zagorova et al. 2015), atherosclerosis (Santanam et al. 2004), diabetic nephropathy (Hernandez-Salinas et al. 2013), altered GIT motility (Muthna et al. 2013) and malignant or inflammatory diseases (Backhouse et al. 1994, Tomsik et al. 2016). These effects were the result of the antioxidant, anti-inflammatory, anti-proliferative, prokinetic, choleretic and anti-infective action of boldine (O'Brien et al. 2006, Muthna et al. 2013). The majority of these pathologies demand long-term repeated administration, preferably orally. Information about bioavailability (BAV), the achievement of the desired concentration in plasma, distribution and elimination, i.e. pharmacokinetics (PK), is therefore crucial for further effective use of boldine. In contrast to detailed data about the effects/pharmacodynamics, much less is known about the PK of the agent.

In the few studies conducted so far, boldine plasma and tissue concentration have been analysed in rats (Jimenez and Speisky 2000, Hroch et al. 2013). The results of these studies consistently showed a rapid decline in boldine plasma concentrations with a terminal half-life of $31 \mathrm{~min}$. Other PK parameters that describe BAV, distribution or metabolism and excretion are 
missing. Only Jimenez et al. (2000) have provided more specific data. Their study demonstrated that treatment of urine samples with $\beta$-glucuronidase increased the recovery of boldine three to four-fold. This produced indirect evidence of the extensive formation of boldine glucuronides. Following this, more detailed analysis through the use of the LC-MS method confirmed glucuronide and sulfate conjugates as the major metabolites of boldine in rats (Hroch et al. 2013). Our group recently showed that concentrations of boldine in bile exceed its concentrations in plasma (Hroch et al. 2013, Cermanova et al. 2015). This means that the agent is actively concentrated in bile by an $\mathrm{ABC}$ transporter on the apical membrane of hepatocytes. Considering substrate spectra, sulfate and glucuronide conjugated metabolites are typically transported by multidrug resistance-associated protein 2 (Mrp2) (Nies and Keppler 2007). The role of Mrp2 in the kinetics of boldine is unknown. Our previous experiments with the infusion of boldine into Mrp2-deficient rats did not show a discrepancy in the choleretic activity of the compound or an inhibitory effect on Mrp2 in MDCK-MRP2 cells (Cermanova et al. 2015). It is therefore important to perform a direct kinetic study in Mrp2-deficient animals to uncover the exact role of Mrp2 in the disposition of boldine.

The aim of this study was to describe the PK of boldine with the specification of individual parameters in control and Mrp2-deficient rats. Special attention was paid to the BAV of the agent and its elimination by hepatic and renal pathways. The contribution of glucuronidation and sulfation to these processes was determined by the incubation of plasma, bile and urine samples with $\beta$-glucuronidase, which also contained sulfatase.

\section{Materials and Methods}

\section{Chemicals}

Boldine was purchased from Sigma-Aldrich (St. Louis, MO, US) and dissolved in distilled water $(\mathrm{pH}$ adjusted by $\mathrm{HCl}$ to 1.0 ) with consequent titration to pH 7.0 by $\mathrm{NaOH}$. The stock solution of boldine was further dissolved in saline for oral and intravenous administration to rats. $\beta$-glucuronidase Type HP2 from Helix pomatia was purchased from Sigma-Aldrich (Cat. no. G7017, St. Louis, MO, US).
Animals

Mrp2-deficient Lewis transport-deficient rats $\left(\mathrm{TR}^{-}\right.$) or complementary Lewis (LW) rats (Institut für Pathophysiologie, Karlsburg, Germany) were used throughout the study. The animals were housed within controlled environmental conditions. All experiments were performed in accordance with the "Guide for the Care and Use of Laboratory Animals" published by the US National Institutes of Health (NIH publication, 1996) and under the supervision of the Ethical Committee of the Faculty of Medicine in Hradec Kralove.

\section{Experimental design}

The examination of BAV was performed in $12 \mathrm{TR}^{-}$and $12 \mathrm{LW}$ rats. Animals from each strain were randomised into two groups (six animals per group). After 12 hours of fasting, one group of $\mathrm{LW}$ and $\mathrm{TR}^{-}$rats received boldine by i.v. bolus $(10 \mathrm{mg} / \mathrm{kg}$ of bw) and another group of $\mathrm{LW}$ and $\mathrm{TR}^{-}$rats were applied with the same dose orally via intragastric probe. Blood samples $(300 \mu \mathrm{l})$ were taken from the orbital plexus in short inhaled anesthesia at 4, 10, 30, 60, 120 and 180 min after the administration of boldine. Plasma was obtained by immediate centrifugation at $3000 \mathrm{~g}$ and stored at $-80^{\circ} \mathrm{C}$. At the end of the experiment, the rats were sacrificed by exsanguination from the carotid artery.

\section{Clearance study}

The evaluation of biliary and urinary excretion of boldine was performed in $\mathrm{LW}$ and $\mathrm{TR}^{-}$rats after 12 hour of fasting (one group each, six rats per group) during general anaesthesia induced by pentoparbital $(50 \mathrm{mg} / \mathrm{kg}$, intraperitoneally). The rats were fixed in a supine position on a heated platform to maintain body temperature at $37^{\circ} \mathrm{C}$ and the v. jugularis (for substance administration), carotid artery (for blood sampling), bile duct (bile collection) and urine bladder (for urine collection) were cannulated. After an initial 30-min stabilisation period, the study began with boldine i.v. bolus of $15 \mathrm{mg} / \mathrm{kg}$ applied over $10 \mathrm{~min}$ followed by an i.v. infusion of boldine $(50 \mathrm{mg} / \mathrm{kg} / \mathrm{h})$. A parallel evaluation of the glomerular filtration rate was enabled by the simultaneous administration of sinistrin $(1.62 \mathrm{mg} / \mathrm{kg} / \mathrm{h})$. The infused volume was $6 \mathrm{ml} / \mathrm{kg} / \mathrm{h}$ to replace fluid losses. Bile and urine were collected in preweighted tubes at 30-min intervals. Blood samples were taken in the middle of the collection intervals. At the end of the experiment, the rats were sacrificed by exsanguination from the carotid artery and samples of 
plasma, bile, urine, liver and kidney were snap frozen in liquid nitrogen and stored at $-80^{\circ} \mathrm{C}$ until analysis.

\section{Western blot}

This method was performed as described previously (Kadova et al. 2015). Briefly, crude membrane fraction from the liver and the kidney was prepared by ultracentrifugation (100000 $\mathrm{g}$ for $1 \mathrm{~h}$ ) of supernatant obtained by centrifugation (3000 $\mathrm{g}$ for $10 \mathrm{~min}$ ) of tissue homogenate. Samples were then separated on polyacrylamide gels, transferred to PVDF membrane and processed by primary and secondary antibodies with consequent chemiluminescent detection. GAPDH was used as a loading control.

\section{Analytical methods}

Boldine was detected by the previously described HPLC method (Hroch et al. 2013). For the identification of phase II boldine metabolites (conjugates) in body fluids, $50 \mu \mathrm{l}$ of urine or bile $(250 \mu \mathrm{l}$ plasma $)$ was mixed with $50 \mu \mathrm{l}$ (250 $\mu 1$ plasma) of acetate buffer ( $\mathrm{pH} 5$; $59 \mathrm{ml}$ of $0.2 \mathrm{M}$ acetic acid and $141 \mathrm{ml}$ of $0.2 \mathrm{M}$ sodium acetate) and $50 \mu \mathrm{l}$ of $\beta$-glucuronidase (or only acetate buffer $\mathrm{pH} 5$ ) was added. The mixture was incubated at $37^{\circ} \mathrm{C}$ for $16 \mathrm{~h}$ (Nobilis et al. 2004). After centrifugation (10000 $\mathrm{g}$ for $5 \mathrm{~min}$ ), the diluted samples (plasma) were directly injected into the chromatographic column. Samples of bile and urine were then diluted with mobile phase and analysed for boldine.

\section{PK analysis}

The calculation of the PK parameters after the bolus i.v. dose of boldine was completed by a noncompartmental analysis of plasma concentration versus time curves using Kinetica software (Thermo Fisher Scientific, Inc.), as reported previously (Laho et al. 2016). The evaluation of biliary and urinary excretion of boldine was performed during constant i.v. infusion of the agent. Biliary and urinary excretion was calculated by multiplication of bile/urine flow ( $\mathrm{ml} / \mathrm{min})$ with the concentration of boldine in the sample (measured before and after treatment with $\beta$-glucuronidase). Clearance parameters were evaluated during steady-state of plasma concentrations, which was reached between 60-120 min of the clearance study. The calculation was based on the division of the rate of administration (for total clearance) or biliary/renal excretion (for biliary/renal clearance) by the steady-state concentration of boldine in plasma. The glomerular filtration rate was calculated as the total clearance of sinistrin during the clearance study by the division of the rate of administration by its plasma concentrations.

\section{Statistical analysis}

The results are presented as mean $\pm \mathrm{SD}$. Students't-test was employed for a two-group comparison. Differences were considered significant at a $p$-value of less than 0.05. All analyses were performed using GraphPad Prism 6.0 software (San Diego, US).

\section{Results}

PK parameters of boldine after bolus administration to control LW animals

Oral and i.v. bolus doses of boldine yielded markedly different profiles of concentrations in plasma of the LW animals (Fig. 1). The ratio of areas under the curve of plasma concentrations $\left(\mathrm{AUC}_{0-\infty}\right)$ pointed to very low BAV (Table 1). The concentration in plasma fell rapidly below the limit of detection, especially in animals who received oral administration. An analysis of the PK parameters was therefore possible only in i.v.-applied animals. Extrapolated AUC from the last measured concentration till infinity was below $2 \%$, which supports the optimal duration of evaluation and guarantees the accuracy of further calculations. Short half-life $\left(T_{1 / 2}\right)$ emphasized the rapid elimination of boldine, as confirmed by the high total clearance of the agent. The profile of plasma concentrations during elimination suggested first order kinetic with single compartment distribution, i.e. avid equilibrium between plasma and tissues. This was also supported by the rapid attainment of maximum concentration $\left(\mathrm{C}_{\max }\right)$ within $4 \mathrm{~min}$, even after oral administration. The distribution volume above volume of total body water (Table 1) indicated the effective intracellular penetration of boldine and complied with its ability to perform an anti-oxidative effect within the cells.

PK parameters after bolus administration to Mrp2deficient $T R^{-}$rats

The plasma concentration versus time plots after i.v. administration of boldine in $\mathrm{TR}^{-}$rats demonstrated a significant increase in $\mathrm{C}_{\max }$ and the prolongation of the elimination phase in comparison with LW animals (Fig. 1). Consequent PK analysis confirmed that Mrp2 deficiency increased $\mathrm{AUC}_{0-\infty}$, prolonged $\mathrm{T}_{1 / 2}$ mean residence time (MRT) and reduced total clearance and 

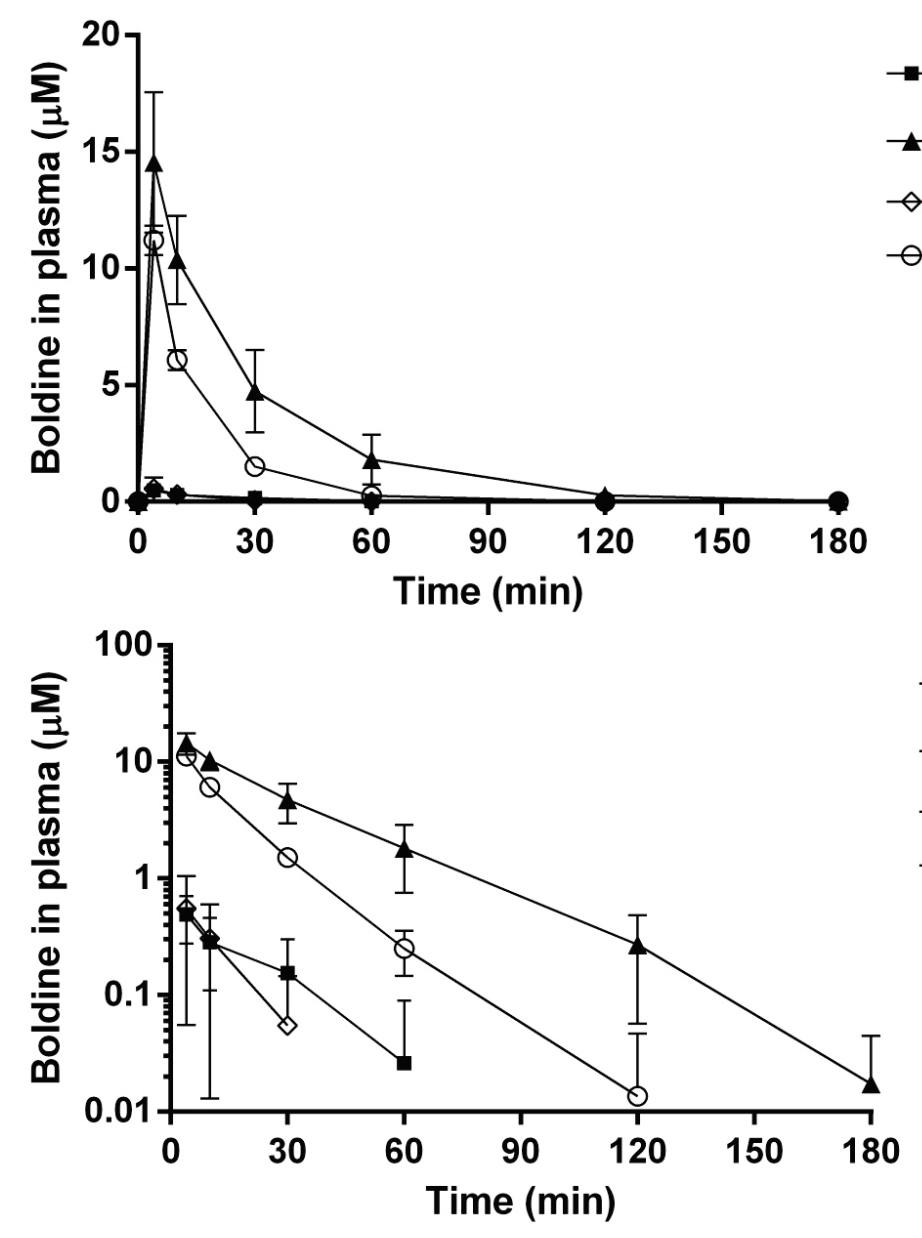

Fig. 1. Plasma concentration time curves of boldine administered $(10 \mathrm{mg} / \mathrm{kg})$ orally or intravenously to LW, control and Mrp2-deficient $\mathrm{TR}^{-}$rats. Data are means $\pm \mathrm{SD}$ (six animals per group).

distribution volume of boldine. Although a tendency towards the prolongation of the elimination period was also evident after the oral administration of boldine in $\mathrm{TR}^{-}$rats (Fig. 1), the interindividual variability precluded the attainment of a statistically significant change of $\mathrm{AUC}_{0-\infty}$ when compared with oral administration in $\mathrm{LW}$ rats. Thus, the ration of $\mathrm{AUC}_{0-\infty}$ after oral and intravenous administration of boldine showed reduced bioavailability of the agent in $\mathrm{TR}^{-}$rats when compared to control LW rats as a consequence of prolonged elimination.

\section{Elimination of boldine in heathy $L W$ rats}

A constant rate infusion of boldine with an analysis of urine and bile in LW rats showed preferential urinary excretion of boldine (Table 2). The ratio of renal clearance to the glomerular filtration rate markedly below one uncovered active reabsorption of the parent compound in renal tubules. The sum of biliary and renal clearances formed less than $2 \%$ of the total clearance, indicating the significant contribution of metabolism to the total clearance of boldine. The consequent incubation of all samples with $\beta$-glucuronidase markedly increased the recovery of boldine and pointed to mainly biliary excretion of boldine conjugates. The total clearance of boldine conjugates approached $38 \%$ of the total clearance of the parent compound.

\section{Elimination of boldine in $T R^{-}$rats}

The absence of Mrp2 in $\mathrm{TR}^{-}$rats led to a marked reduction of biliary excretion and clearance of boldine during its infusion, while its urinary excretion and clearance was increased. As a consequence, the steadystate plasma concentration and total clearance of parent compound were not changed in $\mathrm{TR}^{-}$rats when compared with LW animals. In comparison, biliary excretion and the clearance of boldine conjugates were nearly abolished in $\mathrm{TR}^{-}$rats. Increased urinary excretion was not sufficient to compensate for the reduced biliary excretion of boldine conjugates. Thus, $\mathrm{TR}^{-}$rats showed reduced total clearance of conjugated boldine metabolites with their accumulation in plasma. 
Table 1. The effect of an Mrp2 transporter deficit on the primary PK parameters of boldine after i.v. administration in a dose of $10 \mathrm{mg} / \mathrm{kg}$.

\begin{tabular}{lcc}
\hline & $\mathbf{L W}$ & $\mathbf{T R}^{-}$ \\
\hline$C_{\max }(\mu \mathrm{M})$ & $11 \pm 0.6$ & $15 \pm 3.0^{*}$ \\
$A U C_{0-\infty}(\mathrm{mg} / \mathrm{ml} / \mathrm{min})$ & $0.05 \pm 0.01$ & $0.13 \pm 0.04^{* *}$ \\
$A U C_{\text {extra }}(\%)$ & $1.9 \pm 0.7$ & $1.7 \pm 1.1$ \\
$T_{1 / 2}(\mathrm{~min})$ & $12 \pm 4.6$ & $20 \pm 4.4^{*}$ \\
$M R T(\mathrm{~min})$ & $17 \pm 2.9$ & $30 \pm 6.6^{* *}$ \\
$C L_{T o t}(\mathrm{~m} / \mathrm{min} / \mathrm{kg})$ & $187 \pm 17$ & $88 \pm 40^{* * *}$ \\
$V_{d}(l / \mathrm{kg})$ & $3.2 \pm 0.4$ & $2.4 \pm 0.4^{* *}$ \\
$B A V(\%)$ & 7 & 4.5 \\
\hline
\end{tabular}

LW - control group; $\mathrm{TR}^{-}$- Mrp2-deficient group; $\mathrm{C}_{\max }$ - peak plasma concentration; $\mathrm{AUC}_{0-\infty}$ - area under the plasma concentration curve extrapolated to infinity; $A \cup C_{\text {extra }}-\%$ of extrapolation of $A U C_{0-\infty}$ from last measured concentration to infinity; $T_{1 / 2}$ - elimination half-life; MRT - mean residence time of a drug in the body; $\mathrm{CL}_{\text {Tot }}(\mathrm{ml} / \mathrm{min} / \mathrm{kg})$ - total clearance; $\mathrm{V}_{\mathrm{d}}$ - apparent volume of distribution; BAV bioavailability of the drug. Data are presented as means \pm SD from groups of six animals significantly different from the control group $\left({ }^{*} p<0.05,{ }^{* *} p<0.01,{ }^{* * *} p<0.001\right)$.

Table 2. Comparison between renal and biliary clearance of boldine and its conjugates with glucuronic acid and sulphate during i.v. infusion.

Boldine

Boldine conjugates

LW $\quad$ TR $^{-} \quad$ LW $\quad$ TR $^{-}$

\begin{tabular}{lcccc}
\hline$C_{S S}(\mu \mathrm{M})$ & $29 \pm 5.5$ & $33 \pm 6.6$ & $80 \pm 16$ & $150 \pm 56^{*}$ \\
$B E(\mathrm{nmol} / \mathrm{min} / \mathrm{kg})$ & $3.4 \pm 0.3$ & $1.7 \pm 0.7^{* * *}$ & $240 \pm 46$ & $29 \pm 18^{* * *}$ \\
$U E(\mathrm{nmol} / \mathrm{min} / \mathrm{kg})$ & $13 \pm 7.7$ & $26 \pm 12^{*}$ & $68 \pm 36$ & $270 \pm 100^{* *}$ \\
$C L_{B}(\mathrm{ml} / \mathrm{min} / \mathrm{kg})$ & $0.12 \pm 0.03$ & $0.06 \pm 0.03^{* *}$ & $3.1 \pm 0.73$ & $0.23 \pm 0.17^{* * *}$ \\
$C L_{R}(\mathrm{ml} / \mathrm{min} / \mathrm{kg})$ & $0.42 \pm 0.24$ & $0.75 \pm 0.28^{*}$ & $0.91 \pm 0.58$ & $1.8 \pm 0.6^{*}$ \\
$C L_{R} / \mathrm{GFR}$ & $0.17 \pm 0.12$ & $0.24 \pm 0.15$ & $0.3 \pm 0.1$ & $0.5 \pm 0.12^{*}$ \\
$C L_{T o t}(\mathrm{ml} / \mathrm{min} / \mathrm{kg})$ & $53 \pm 9.1$ & $49 \pm 9.2$ & $20 \pm 3.5$ & $11 \pm 3.5^{* *}$ \\
\hline
\end{tabular}

LW - control group; TR - Mrp2-deficient group; $\mathrm{C}_{S S}$ - steady-state plasma concentration; BE - biliary excretion; UE - urinary excretion; $\mathrm{CL}_{B}$ - biliary clearance; $\mathrm{CL}_{R}$ - renal clearance; $\mathrm{CL}_{\text {Tot }}$ - total body clearance; GFR - glomerular filtration rate. Data are presented as means \pm SD from groups of six animals significantly different from the control group $\left({ }^{*} p<0.05\right.$, ${ }^{* *} p<0.01$, *** $p<0.001)$.

Protein expression of selected transporters in the liver and kidney

Western blot analysis of the major drugtransporting proteins showed the sole absence of Mrp2 in the liver of $\mathrm{TR}^{-}$rats without influence on other proteins (Fig. 2A). Mrp2 was also nearly absent in kidneys but herein we also detected a reduced expression of uptake Oat1 and Oat 3 transporters and an increased expression of Mrp4 (Fig. 2B).

\section{Discussion}

Bioavailability is an essential PK parameter describing the proportion of the dose applied by extravascular administration that reaches systemic circulation in an active form. Knowledge of these parameters is extremely important for agents, which are intended for mainly oral application. The value of BAV for boldine was not known. In the only study presenting plasma concentration versus time plots of boldine in rats after oral or i.v. administration, the authors used different doses and different timings for blood sampling for either application route (Jimenez and Speisky 2000). Only a rough comparison was possible between the administration of $20 \mathrm{mg} / \mathrm{kg}$ intravenously and $25 \mathrm{mg} / \mathrm{kg}$ of boldine orally. Under these settings, average $\mathrm{C}_{\max }$ after intravenous administration was approximately $31 \mu \mathrm{M}$, while the oral dose yielded a concentration of $7 \mu \mathrm{M}$. 
A
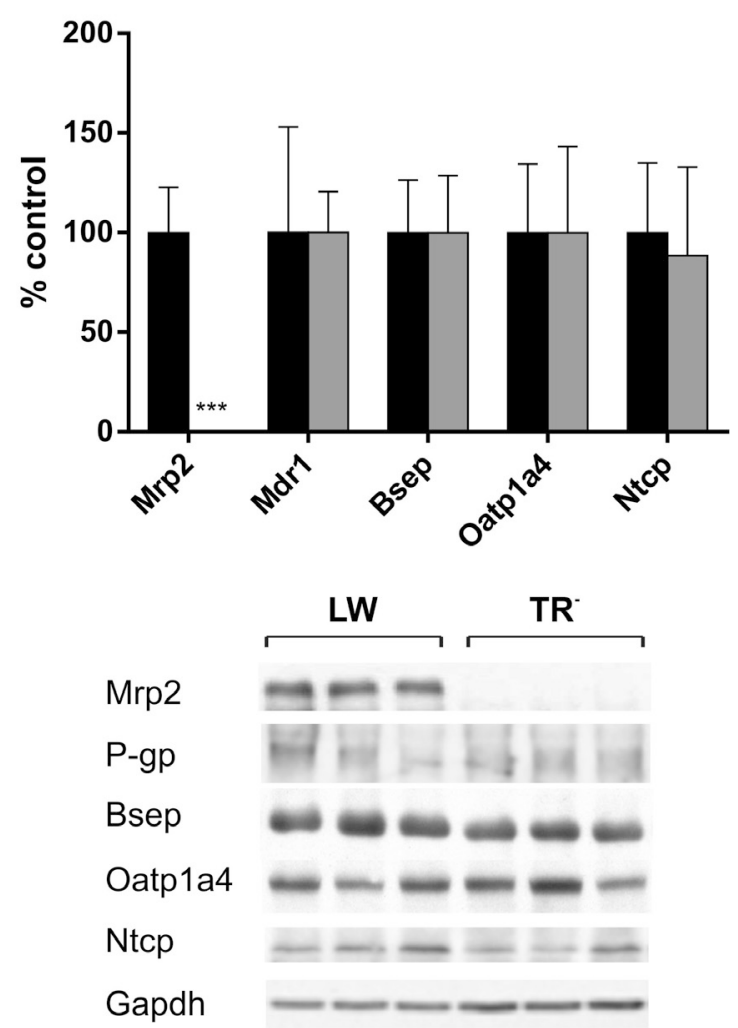

B
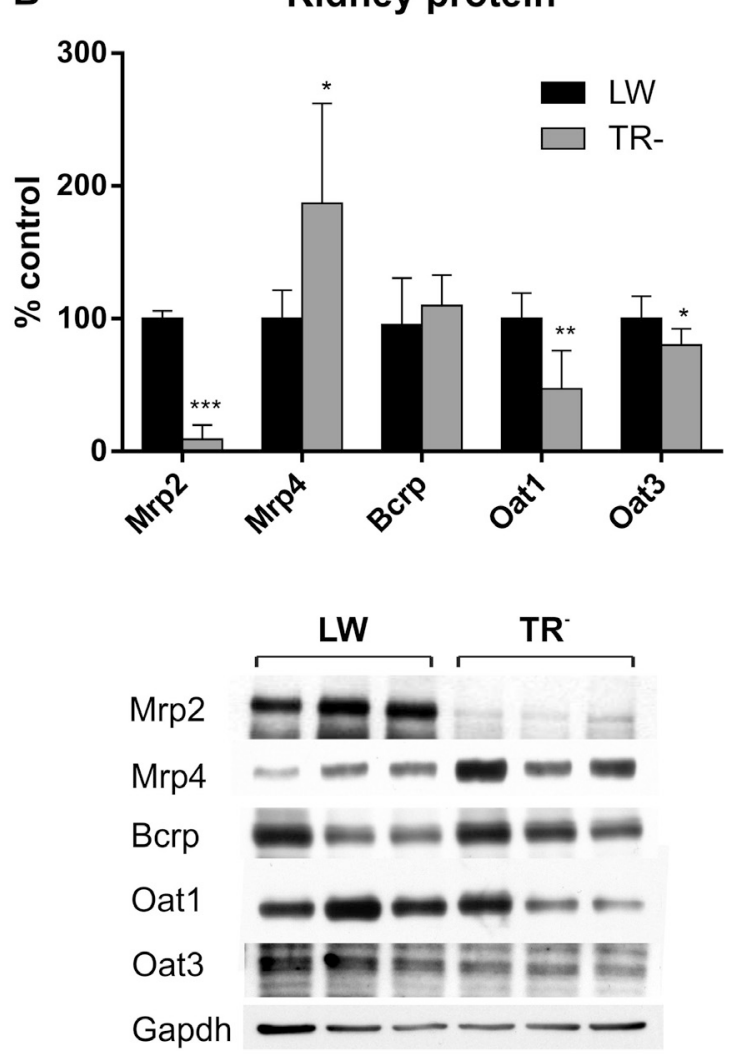

Fig. 2. Protein expression of selected drug transporters in the liver (A) and kidneys (B) of $L W$ and $T R^{-}$rats. Bands present representative analysis of six animals per group. Asterisks show significant difference from control group $\left({ }^{*} p<0.05,{ }^{* *} p<0.01\right.$, $\left.{ }^{* *} p<0.001\right)$.

Within $60 \mathrm{~min}$ of administration, plasma concentrations declined to $5 \mu \mathrm{M}$ and to $3 \mu \mathrm{M}$ after intravenous and oral administration, respectively. Differences in $\mathrm{C}_{\max }$ therefore suggest poor absorption of boldine from GIT. Our data from the administration of $10 \mathrm{mg} / \mathrm{kg}$ by both routes and the standardization of blood sampling yielded very low oral bioavailability of $7 \%$. The exact cause of low BAV of boldine is unknown. A major problem seems to be the reduced water solubility of the agent at a physiological or slightly basic $\mathrm{pH}$ in the intestine. The agent is most soluble in an acidic environment, as detected in dissolution experiments during the optimization of administration (unpublished observation). This may explain the extremely rapid absorption of boldine from the stomach after its gastric gavage when $\mathrm{C}_{\max }$ was attained within $4 \mathrm{~min}$. An important implication of low BAV of boldine in terms of further oral administration is that the agent must be applied in sufficiently large doses to reach the plasma and tissue concentrations required for its health-promoting effect. Necessary concentrations for its intense free radical scavenging properties are 10-50 $\mu \mathrm{M}$ (Muthna et al. 2013). Together with low BAV, this means that a boldine oral dose of at least $10 \mathrm{mg}$ per kg of BW must be applied to produce the chance of a sufficient pharmacodynamic response. A combination of large doses with low BAV may consequently produce high local concentrations of boldine in GIT. Furthermore, the intensive topical effect of rectally-applied boldine was demonstrated by the suppression of inflammation in experimental colitis (Gotteland et al. 1997).

The PK parameters and the routes of boldine elimination from organisms were completely unknown. The only available data showed a very short plasma elimination half-life of $31 \mathrm{~min}$ (Jimenez and Speisky 2000). The administration of boldine to control LW animals in our study demonstrated an even shorter halflife of $12 \mathrm{~min}$. An explanation for such a difference is still needed. The difference may be the effect of strain difference when compared with previously used Wistar rats. We also note that i.v. sampling under short anesthesia in our study reduced the stress of animals compared to immobilisation used in the previous study. The rapid elimination of boldine after the i.v. bolus injection corresponded with its high total clearance. However, the bile and urine sampling indicated that bile and renal clearance of the parent compound formed only 
$1 \%$ of the total clearance. The study showed that boldine is mainly metabolized. Previous studies detected glucuronide and/or sulfate conjugates as major metabolites of boldine (Hroch et al. 2013). Indeed, treatment of samples with $\beta$-glucuronidase also containing sulfatase increased the recovery of boldine, particularly from bile. The clearance of boldine by these enzymatic pathways consequently formed at least $38 \%$ of the total clearance of the compound. The pathway eliminating the remaining part of the administered dose is unknown. However, the major drawback of the study is that the exact concentration of glucuronide and sulfate conjugates could not be exactly measured due to the unavailability of the LC-MS/MS method. Therefore our data may have underestimated the contribution of conjugation to overall clearance. On the other hand, the method was able to compare the mutual contribution of biliary and renal clearance and showed preferential renal excretion of the parent compound. The conjugated metabolites revert this ration in favor of biliary excretion, pointing to their higher affinity for apical transporting proteins in hepatocytes. An interesting finding was also the marked reabsorption of boldine, as well as its conjugates, in kidney tubules. Whether this effect is carried out by passive reabsorption or active transport deserves further research.

Sulfate and glucuronide conjugates, which seem to be a major elimination pathway for boldine (Hroch et al. 2013), are typically transported by the Mrp2 protein (Nies and Keppler 2007). We therefore compared the kinetics of boldine between control and Mrp2-deficient animals. A significant prolongation of the elimination phase after the bolus i.v. administration of boldine and its reduced biliary excretion during infusion in $\mathrm{TR}^{-}$rats confirmed the important role of Mrp2 in the elimination of boldine itself. Moreover, the incubation of samples with glucuronidase/sulfatase uncovered a massive reduction in biliary secretion of these boldine conjugates in Mrp2deficient animals and showed that Mrp2 is a major transporter for these metabolites in the liver. The opposite occurred in the kidneys, where an Mrp2 deficit led to increased urinary excretion and renal clearance of boldine as well as its conjugates. This increase corresponds with the up-regulation of the Mrp4 transporter seen in current and previous studies (Chen et al. 2005). The shared substrate specificity between Mrp2 and Mrp4 (Deeley et al. 2006, Zhou et al. 2008) supports the role of Mrp4 in the elimination of boldine and its metabolites.

Another factor that must be considered is a possible change in the activity of glucuronosyltransferases in Mrp2-deficient rats. Johnson et al. (2006) reported a 3.5-5.5-fold higher expression of the UGT1A enzyme family proteins in the liver and kidney of $\mathrm{TR}^{-}$rats compared to wild-type rats. This mechanism is supported by markedly increased plasma concentrations of boldine conjugates and a rise in their urinary excretion. In addition, the Mrp3 basolateral protein, which serves as a cytoprotective mechanism by transporting Mrp2 substrates including conjugates with glucuronic acid from hepatocytes and proximal tubular cells back to blood, is also augmented in the liver and kidney of $\mathrm{TR}^{-}$animals, as previously reported (Johnson et al. 2006).

The Mrp2 transporter is also localised at the apical membrane of enterocytes and it reduces the absorption of its substrates. The absence of this transporter is therefore associated with the increased bioavailability of such compounds (Dahan and Amidon 2009, Zamek-Gliszczynski et al. 2012). However, Mrp2 deficiency does not seem to modify the absorption of boldine from GIT because $\mathrm{TR}^{-}$rats demonstrated reduced bioavailability. We suggest that this reduction rose from unchanged $\mathrm{AUC}_{0-\infty}$ after oral administration between control and $\mathrm{TR}^{-}$animals and increased $\mathrm{AUC}_{0-\infty}$ due to the prolongation of the elimination phase in $\mathrm{TR}^{-}$animals after the i.v. bolus of boldine. Comparable $\mathrm{AUC}_{0-\infty}$ after oral administration in $\mathrm{LW}$ and $\mathrm{TR}^{-}$rats indicates the involvement of other intestinal transporters in the absorption of boldine. Indeed, Johnson et al. (2006) described marked down-regulation of the Mrp3 protein in the jejunum and ileum of $\mathrm{TR}^{-}$rats. Mrp3 is an efflux transporter at the basolateral membrane of enterocytes, which facilitates the absorption of compounds from GIT. It is therefore possible that similar substrate specificity with Mrp2 also enables the transportation of boldine by Mrp3 and that the reduction of Mrp3 in enterocytes compensates for the absence of Mrp2.

In conclusion, our study has demonstrated for the first time low bioavailability, intracellular distribution and quantification of mutual hepatic and renal elimination of boldine in rats. We have also noted the significant role of Mrp2 and conjugation with glucuronic acid and sulphates in the overall PK of boldine. The results also indicated that boldine may be a substrate for other Mrp members, namely Mrp4.

\section{Conflict of Interest}

There is no conflict of interest. 


\section{Acknowledgements}

This study was supported by grants from the Grant
Agency of Charles University Prvouk P37/05 and SVV2016-260287.

\section{References}

BACKHOUSE N, DELPORTE C, GIVERNAU M, CASSELS BK, VALENZUELA A, SPEISKY H: Antiinflammatory and antipyretic effects of boldine. Agents Actions 42: 114-117, 1994.

CERMANOVA J, KADOVA Z, ZAGOROVA M, HROCH M, TOMSIK P, NACHTIGAL P, KUDLACKOVA Z, PAVEK P, DUBECKA M, CECKOVA M, STAUD F, LAHO T, MICUDA S: Boldine enhances bile production in rats via osmotic and farnesoid X receptor dependent mechanisms. Toxicol Appl Pharmacol 285: 12-22, 2015.

CHEN C, SLITT AL, DIETER MZ, TANAKA Y, SCHEFFER GL, KLAASSEN CD: Up-regulation of Mrp4 expression in kidney of Mrp2-deficient TR- rats. Biochem Pharmacol 70: 1088-1095, 2005.

DAHAN A, AMIDON GL: Small intestinal efflux mediated by MRP2 and BCRP shifts sulfasalazine intestinal permeability from high to low, enabling its colonic targeting. Am J Physiol Gastrointest Liver Physiol 297: G371-G377, 2009.

DEELEY RG, WESTLAKE C, COLE SP: Transmembrane transport of endo- and xenobiotics by mammalian ATPbinding cassette multidrug resistance proteins. Physiol Rev 86: 849-899, 2006.

FERNANDEZ J, LAGOS P, RIVERA P, ZAMORANO-PONCE E: Effect of boldo (Peumus boldus Molina) infusion on lipoperoxidation induced by cisplatin in mice liver. Phytother Res 23: 1024-1027, 2009.

GOTTELAND M, JIMENEZ I, BRUNSER O, GUZMAN L, ROMERO S, CASSELS BK, SPEISKY H: Protective effect of boldine in experimental colitis. Planta Med 63: 311-315, 1997.

HERNANDEZ-SALINAS R, VIELMA AZ, ARISMENDI MN, BORIC MP, SAEZ JC, VELARDE V: Boldine prevents renal alterations in diabetic rats. J Diabetes Res 2013: 593672, 2013.

HROCH M, MICUDA S, CERMANOVA J, CHLADEK J, TOMSIK P: Development of an HPLC fluorescence method for determination of boldine in plasma, bile and urine of rats and identification of its major metabolites by LC-MS/MS. J Chromatogr B Analyt Technol Biomed Life Sci 936: 48-56, 2013.

JIMENEZ I, SPEISKY H: Biological disposition of boldine: in vitro and in vivo studies. Phytother Res 14: 254-260, 2000.

JOHNSON BM, ZHANG P, SCHUETZ JD, BROUWER KL: Characterization of transport protein expression in multidrug resistance-associated protein (Mrp) 2-deficient rats. Drug Metab Dispos 34: 556-562, 2006.

KADOVA Z, DOLEZELOVA E, CERMANOVA J, HROCH M, LAHO T, MUCHOVA L, STAUD F, VITEK L, MOKRY J, CHLADEK J, HAVLINOVA Z, HOLECEK M, MICUDA S: IL-1 receptor blockade alleviates endotoxin-mediated impairment of renal drug excretory functions in rats. Am $J$ Physiol Renal Physiol 308: F388-F399, 2015.

LAHO T, CLARKE JD, DZIERLENGA AL, LI H, KLEIN DM, GOEDKEN M, MICUDA S, CHERRINGTON NJ: Effect of nonalcoholic steatohepatitis on renal filtration and secretion of adefovir. Biochem Pharmacol 115: 144-151, 2016.

LANHERS MC, JOYEUX M, SOULIMANI R, FLEURENTIN J, SAYAG M, MORTIER F, YOUNOS C, PELT JM: Hepatoprotective and anti-inflammatory effects of a traditional medicinal plant of Chile, Peumus boldus. Planta Med 57: 110-115, 1991.

MUTHNA D, CMIELOVA J, TOMSIK P, REZACOVA M: Boldine and related aporphines: from antioxidant to antiproliferative properties. Nat Prod Commun 8: 1797-1800, 2013.

NIES AT, KEPPLER D: The apical conjugate efflux pump ABCC2 (MRP2). Pflugers Arch 453: 643-659, 2007.

NOBILIS M, HOLCAPEK M, KOLAROVA L, KOPECKY J, KUNES M, SVOBODA Z, KVETINA J: Identification and determination of phase II nabumetone metabolites by high-performance liquid chromatography with photodiode array and mass spectrometric detection. J Chromatogr A 1031: 229-236, 2004.

O'BRIEN P, CARRASCO-POZO C, SPEISKY H: Boldine and its antioxidant or health-promoting properties. Chem Biol Interact 159: 1-17, 2006. 
SANTANAM N, PENUMETCHA M, SPEISKY H, PARTHASARATHY S: A novel alkaloid antioxidant, Boldine and synthetic antioxidant, reduced form of RU486, inhibit the oxidation of LDL in-vitro and atherosclerosis in vivo in LDLR(-/-) mice. Atherosclerosis 173: 203-210, 2004.

TOMSIK P, MICUDA S, MUTHNA D, CERMAKOVA E, HAVELEK R, RUDOLF E, HROCH M, KADOVA Z, REZACOVA M, CMIELOVA J, ZIVNY P: Boldine inhibits mouse mammary carcinoma in vivo and human MCF-7 breast cancer cells in vitro. Planta Med 82: 1416-1424, 2016.

ZAGOROVA M, PRASNICKA A, KADOVA Z, DOLEZELOVA E, KAZDOVA L, CERMANOVA J, ROZKYDALOVA L, HROCH M, MOKRY J, MICUDA S: Boldine attenuates cholestasis associated with nonalcoholic fatty liver disease in hereditary hypertriglyceridemic rats fed by high-sucrose diet. Physiol Res $\mathbf{6 4}$ (Suppl. 4): S467-S476, 2015.

ZAMEK-GLISZCZYNSKI MJ, BEDWELL DW, BAO JQ, HIGGINS JW: Characterization of SAGE Mdr1a (P-gp), Bcrp, and Mrp2 knockout rats using loperamide, paclitaxel, sulfasalazine, and carboxydichlorofluorescein pharmacokinetics. Drug Metab Dispos 40: 1825-1833, 2012.

ZHOU SF, WANG LL, DI YM, XUE CC, DUAN W, LI CG, LI Y: Substrates and inhibitors of human multidrug resistance associated proteins and the implications in drug development. Curr Med Chem 15: 1981-2039, 2008. 